\title{
La recepción de Las penas del joven Werther de J. W. Goethe en el contexto de la Segunda llustración. La reseña de Friedrich Blanckenburg
}

\author{
[The reception of J. W. Goethe's The Sorrows of Young Werther in the context of the \\ Second Enlightenment. The review by Friedrich Blanckenburs] \\ http://dx.doi.org/10.11606/1982-8837244396
}

Martín Isnacio Koval ${ }^{1}$

\begin{abstract}
We discuss here Friedrich Blanckenburg's review of J. W. Goethe's The Sorrows of Young Werther (1774). The review, of which we include the Spanish translation of several passages, was published only a few months later than Goethe's controversial and revolutionary novel and constitutes a valuable document not only of its reception, but also of the theorisation about the genre in the context of the late Second Enlightenment in Germany. Indeed, it accounts for a central feature of this period: the sensible, empfindsam reception, which would have a beneficial effect on sociability and customs. Moreover, in a somewhat ambiguous relationship with this call for the socially useful empathy of the critic and the reader, the author presents elements that point strikingly towards a doctrine of the autonomy of the aesthetic sphere. It remains unclear whether this is due to a "lack of clarity" in the review or a lucid interpretation of the "double voice" proposed by Goethe in his famous epistolary novel.
\end{abstract}

Keywords: Werther's reception; sensibility; theory of the novel; period of the Second Enlightenment.

Resumo: Se discute aquí la reseña de Friedrich Blanckenburg sobre Las penas del joven Werther (1774) de J. W. Goethe. La reseña, de la que ofrecemos la traducción al español de varios pasajes, fue publicada unos meses más tarde que la polémica y revolucionaria novela de Goethe y constituye un documento valioso no solo de su recepción, sino también de la teorización acerca del género en el contexto de finales de la Segunda Ilustración en Alemania. Da cuenta, en efecto, de un rasgo central de este periodo: la recepción sensibilista, empfindsam, que tendría un efecto benefactor sobre la sociabilidad y las costumbres. Además, en una relación en cierto modo ambigua con este llamado a la empatía socialmente útil del crítico y del lector, el autor presenta elementos que señalan llamativamente hacia una doctrina de la autonomía de la esfera estética. Lo que queda sin saberse es si se trata de una "desprolijidad" de la reseña o de una lúcida interpretación de la "voz doble" que plantea Goethe en su famosa novela epistolar.

Palavras-chave: recepción del Werther; sensibilismo; teoría de la novela; Segunda Ilustración.

${ }^{1}$ CONICET - Consejo Nacional de Investigaciones Científicas y Técnicas, Godoy Cruz, 2290, Buenos Aires, C1033AAJ, Argentina. E-mail: martinignaciokoval@gmail.com. ORCID: 0000-0002-3641-5721 
La extensa reseña de Las penas del joven Werther (1774) de J. W. Goethe fue publicada por Christian Friedrich Blanckenburg en la revista Neue Bibliothek der schönen Wissenschaften und freyen Künste (Nueva Biblioteca de las Bellas Ciencias y de las Artes

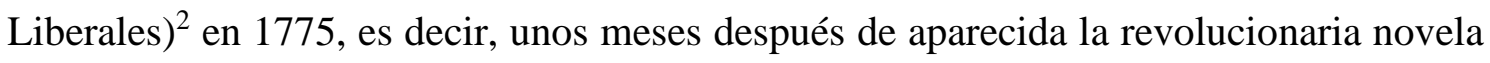
del joven poeta alemán; si bien hoy en día ha quedado en el olvido -también en la academia alemana-, constituye un importante documento de la recepción contemporánea al Werther y, también, de algo parecido a una teoría alemana de la novela, en el contexto de la transición hacia la Spätaufklärung.

Blanckenburg, un nombre seguramente desconocido para el lector hispanolusitano hablante de nuestros días, nació en Kolberg el 24 de enero de 1744, fruto de la unión matrimonial de un noble de Pomerania y una prima del poeta Ewald Christian von Kleist. Entre 1759 y 1776 se desempeñó como oficial de la caballería prusiana, participando, a partir de 1761, de la Guerra de los Siete Años. En 1777, abandonó definitivamente la carrera militar, que nunca llegó a gustarle realmente. A partir de 1778, a instancias de Christian Felix Weiße, con quien mantuvo una relación epistolar entre 1768 y 1778, vivió en Leipzig, ciudad en la que residió hasta su muerte, el 4 de mayo de 1796, dedicado ya exclusivamente a actividades relacionadas con la literatura.

La ocupación de Blanckenburg con las letras tuvo dos facetas: la producción poética y la teoría e historia de la literatura, pero como poeta no gozó de gran éxito. Al parecer, siguiendo el consejo de Weiße, mantuvo sus bocetos dramáticos inéditos; por otro lado, en 1775, muy inspirado por Laurence Sterne, escribió una novela, Beyträge zur Geschichte des deutschen Reichs und deutscher Sitten (Contribuciones a la historia del Imperio alemán y las costumbres alemanas), que quedó inconclusa. Fue empleado en la Biblioteca de Leipzig y se desempeñó como redactor y traductor en distintas revistas. Publicó entre 1786 y 1787 una nueva edición, anotada, de la Allgemeine Theorie der schönen Künste (Teoría general de las bellas artes) de Johann Georg Sulzer ${ }^{3}$ y produjo

\footnotetext{
${ }^{2}$ Se publicó entre 1765 y 1806 . Entre 1757 y 1759, cuando la publicación llevaba el nombre de Bibliothek der schönen Wissenschaften und freyen Künste únicamente, sus editores fueron Friedrich Nicolai y Moses Mendelssohn. A partir de 1759 se hizo cargo de ella Christian Felix Weiße, quien le añadió el adjetivo "neue" (nueva) en 1765.

${ }^{3}$ Diversos autores colaboraron con Sulzer en su confección. Por ejemplo, Christoph Martin Wieland y Johann Jakob Bodmer. En portugués, se puede consultar la entrada "Imaginação (Belas-artes)", traducida y comentada por Ulisses Razzante Vaccari (2008).
}

Pandaemonium, São Paulo, v. 24, n. 43, mai.-ago. 2021, p. 96-110 
KOVAL, M. I. - La recepción de Las penas del joven Werther

textos teóricos y críticos de diversa índole, si bien solo uno de ellos alcanzó una fama perdurable.

La obra con la que Blanckenburg hizo un aporte significativo a la historia y teoría de la literatura es, sin dudas, su Versuch über den Roman (Ensayo sobre la novela), ${ }^{4}$ que publicó en Leipzig en 1774. Baste decir que desde Friedrich Schlegel, pasando por Goethe, Friedrich Schiller, Novalis, Jean Paul, G. W. F. Hegel, y hasta, ya en el siglo XX, György Lukács, Herbert Marcuse y Walter Benjamin, entre otros, se acercan de uno u otro modo, en sus estudios sobre la novela, a las inspiradas consideraciones pioneras este autor (sin que esto implique que se lo pueda reconocer de modo manifiesto, al nivel de la superficie textual). A su vez, ninguna historización de la teoría del famoso (y difamado) género del Bildungsroman (novela de formación) puede considerarse completa ni bien hecha, si no comienza por Blanckenburg ${ }^{5}$.

Blanckenburg parte de una consideración histórico-literaria cercana a la postulada previamente por Johann Gottfried Herder al afirmar que la novela es la forma literaria típica de la modernidad. Basándose en el análisis de varias novelas del siglo XVIII, pero, muy en particular, en el Tom Jones (1749) de Henry Fielding6 y La historia de Agathon $\left(1^{\mathrm{a}}\right.$ ed. 1767) de Christoph Martin Wieland, ${ }^{7}$ afirma que la novela es una sucesora de la epopeya antigua, en la medida en que tiene con esta una tarea en común: reproducir la realidad mediante la narración de sucesos, es decir, como dirá - por poner un ejemploLukács (2011) muchísimo después, por intermedio de la configuración de acciones narradas y no representadas.

Lo que distingue a la novela, empero, de la forma antigua es que en ella se trata de dar cuenta de la historia interior del hombre y no de narrar las hazañas de los héroes. Esto es lo que Blanckenburg descubre como nuevo en la novela de Fielding y, sobre todo, en la de Wieland. Dice el crítico: „[D]ie Ausbildung und Formung, die ein Charakter durch seine mancherley Begegnisse erhalten kann, oder noch eigentlicher, seine innere

\footnotetext{
${ }^{4}$ No existe una traducción al castellano ni -hasta donde sabemos- al portugués de esta importante teoría de la novela.

${ }^{5}$ Para una contextualización de esta discusión, véase Koval (2018: 54ss).

${ }^{6}$ Tom Jones es uno de los principales exponentes de un tipo de novela nacida en Inglaterra e inspirada por el espíritu de la Ilustración. En ella aparecen ya dos elementos de central importancia en la novela como género: la observación realista y el subjetivismo psicológico. El Tom Jones ha sido caracterizado como un Don Quijote burgués.

${ }^{7}$ La historia de Agathon es la primera gran Entwicklungsroman (novela de desarrollo) alemana. Debe ser entendida como una suerte de desarrollo psicológico-filosófico con relación a su predecesor, el Simplicissimus (1668) de Grimmelshausen.
}

Pandaemonium, São Paulo, v. 24, n. 43, mai.-ago. 2021, p. 96-110 
KOVAL, M. I. - La recepción de Las penas del joven Werther

Geschichte, [ist] das Wesentliche und Eigenthümliche [des] Romans“ (2008: 201). La historia interior (,innere Geschichte“) es, así, aquello que se va dando como resultado de la interacción del individuo con los sucesos externos. Blanckenburg, que reconoce influencias de William Shakespeare, Henry Home, Johann Georg Sulzer, Gotthold Ephraim Lessing y Moses Mendelssohn, se refiere al desarrollo de la personalidad y sensibilidad del personaje, así como a su maduración mental y psicosocial.

El autor del Versuch propone una poética y una normativa del género; esto es, su intención no es solo determinar qué es una novela sino, mucho más, qué debe ser. La novela debe representar el proceso por el cual el héroe forma su carácter. No importa tanto la narración de los acontecimientos en los que se ve envuelto, sino el modo en que ellos influyen en el desarrollo de su carácter (y en su sensibilidad). La narración de los acontecimientos es importante únicamente en la medida en que permite explicar cómo el héroe ha llegado a ser lo que es (SELBMANN 1994: 7). El interés por el personaje es del orden de lo antropológico, ya que ayuda a reflexionar acerca de la condición humana. En este punto, la novela (la novela psicológica burguesa, habría que decir) como forma moderna se aleja ya no solo de las formas épicas antiguas, sino también de la novela de peripecias o picaresca.

En el Versuch se persigue también otro objetivo: socavar la idea de que la novela es un género literario menor. Al menos hasta la década del setenta del siglo XVIII, la novela era considerada mera literatura de entretenimiento, dirigida a un público también concebido generalmente como "menor": la mujer. La estrategia de Blanckenburg en este punto consiste en resaltar su presunto valor formativo. La novela se convierte así en una herramienta fundamental para el estudio de lo humano en general: "[Para Blanckenburg,] la novela debe vérselas con hombres y debe enseñarnos a ser hombres" (DE BOOR; NEWALD 1967: 135).

Además, sin ser ya un simple catálogo de máximas morales, la novela debe enseñar, con todo, a formar el carácter (del héroe y del lector) de manera tal que el resultado final sea uno de relativo perfeccionamiento con relación al estadio inicial. El héroe, al igual que el lector, debe ser conducido a un estado de equilibrio que lo aleje del peligro de las egoístas pasiones desenfrenadas y unidimensionales. La figura del lector en el planteo de Blanckenburg, es decir, el nivel de la recepción, se vuelve aún más relevante, como se verá, en la reseña que aquí nos ocupa.

No mucho más tarde que el Versuch, en los primeros meses de 1775, aparece la Pandaemonium, São Paulo, v. 24, n. 43, mai.-ago. 2021, p. 96-110 
KOVAL, M. I. - La recepción de Las penas del joven Werther

reseña crítica de la novela Las penas del joven Werther, que un joven Goethe había publicado poco tiempo antes, en 1774 (algo después de que el Versuch saliera a la luz). La reseña de Blanckenburg representa un esfuerzo por demostrar la manera "correcta" en que se debía leer, en particular, la novela epistolar de Goethe, y, más en general, las obras poéticas. Es decir que este texto de Blanckenburg, al mismo tiempo que constituye una interpretación de la novela goetheana, puede ser considerado como una suerte de contribución a una prototeoría de la recepción. Lo que se propone es, en definitiva, un modelo de lector.

El Werther había suscitado, en seguida, un gran revuelo en el ámbito cultural alemán e incluso europeo. No solo provocó fascinación, sino que la descripción artística verosímil del camino de un joven hacia el suicidio escandalizó en gran medida al clima moralizante y racionalista imperante. En Alemania, los novelistas populares como Samuel Richardson, J.-J. Rousseau, Christian Fürchtegott Gellert o Sophie von La Roche habían sido leídos y aceptados en la medida en que en sus obras triunfaba siempre, en última instancia, la virtud burguesa, y se imponía, tras los rodeos que fueran necesarios, el sensato apaciguamiento de las pasiones.

El Werther contó con detractores "previsibles" entre los adeptos de los semanarios morales: un claro ejemplo es el de Johann Jakob Bodmer. Pero también fue criticado por autores como Friedrich Nicolai y los ya mencionados Sulzer y Lessing -los editores, junto con M. Mendelssohn, de las Briefe, die neueste Literatur betreffend (Cartas acerca de la literatura más reciente), que se publicaron entre 1759 y $1765-^{8}$, quienes no negaban en absoluto la calidad literaria de la novela del joven Goethe, pero sí veían con preocupación una posible relación de complementariedad entre sensibilismo y amoralidad, sobre todo por el "peligro" de que el lector fuera conducido a sentir empatía por un suicida (LEISTNER 1995: 74s.).

Nicolai, por su parte, llegó incluso a proponer una versión "mejorada" de la novela: su Freuden des jungen Werthers (Alegrías del joven Werther), publicada en Berlín a comienzos de 1775 , no solo está enmarcada por un diálogo de intenciones didáctico-ilustradas entre un hombre maduro y un joven atacado por la fiebre wertheriana al que aquel intenta reconducir a la senda de la sensatez, sino que el personaje de Albert es empático y tiene un rol fundamental en la "curación” de Werther.

\footnotetext{
${ }^{8}$ Los autores querían acceder al gran público, por lo que sus contribuciones tenían más el tono de una opinión que el que era común en los críticos de arte contemporáneos.
}

Pandaemonium, São Paulo, v. 24, n. 43, mai.-ago. 2021, p. 96-110 
KOVAL, M. I. - La recepción de Las penas del joven Werther

Frente a todos ellos, Blanckenburg describe la novela en términos casi exclusivamente elogiosos, asumiendo así una postura muy definida en el contexto de la acalorada discusión suscitada por su recepción; si bien, al mismo tiempo, no llega a concordar del todo con jóvenes lectores contemporáneos que, según su parecer, como se desprende de ciertos pasajes de la reseña, se mostraban demasiado "entusiastas" (y, por lo tanto, estaban imposibilitados de asumir una distancia crítica), como sería el caso, podemos pensar, de Christian Daniel Schubart o Wilhelm Heinse.

La reseña sobre Las penas del joven Werther tiene una importancia menor a la del Versuch en la historia de la teoría de la novela en Alemania, pero, con todo, hay muchas razones -incluso en la actualidad- que la vuelven un digno objeto de interés, como lo delata el hecho de que se la incluya en dos de las más importantes compilaciones alemanas de la producción teórica del siglo XVIII: la de Dieter Kimpel y Conrad Wiedemann (1970), y la de Ernst Weber (1981) ${ }^{9}$.

En lo que sigue, nos detendremos en tres aspectos: 1. la forma epistolar y la verosimilitud; 2. la necesidad de una recepción sensibilista antes que moralizante o de censura, y 3. la concepción de la obra de arte como totalidad autónomamente justificada en un sentido estético. La intención es dar cuenta de la posición al mismo tiempo "típica" y "adelantada" que ocupa el autor en el contexto de las discusiones críticas de los últimos años de la Empfinsamkeit. Al mismo tiempo mostrar, en consideración de los dos últimos aspectos, que el reseñista sostiene dos tesis difíciles de conciliar entre sí, sin que él mismo sea consciente o se muestre preocupado por salvar lo que tiene toda la apariencia de ser una contradicción.

\footnotetext{
${ }^{9} \mathrm{Si}$ bien el texto retoma varias consideraciones acerca de la novela como género que ya habían aparecido en el Versuch y, en ese sentido, no es del todo original ni relevante, no deja de resultar de gran interés, por ejemplo, el modo en que Blanckenburg distingue la novela del drama, por ser esta una cuestión que atraviesa una gran parte de la teoría de la novela en Alemania desde las famosas conversaciones entre Wilhelm y Serlo en los Wilhelm Meisters Lehrjahre (1795/96) de Goethe hasta, al menos, Lukács, en Teoría de la novela (1916; publ. como libro en 1920) o "La novela como epopeya burguesa" (1934). La reseña tiene, además, otros sectores novedosos y que revelan la agudeza interpretativa del autor; así, por ejemplo, el "descubrimiento" de que el desenlace de la novela de Goethe (el suicidio del protagonista) ya está contenido, in nuce, en las primeras cartas; se trata de una tesis muy original y productiva, como se ve en el hecho de que fue usada muchísimo más tarde (y de un modo exhaustivo), a mediados del siglo pasado, por un autor como Hans-Egon Hass (1957).
}

Pandaemonium, São Paulo, v. 24, n. 43, mai.-ago. 2021, p. 96-110 


\section{II}

Es llamativo que, en el Versuch, Blanckenburg había considerado que las novelas epistolares no eran adecuadas para la formación del lector, en vista de que en ellas no se da una alternancia entre la escena (cercanía al mundo narrado) y el comentario del narrador (mediación). La idea de Blanckenburg era que recién a partir de las reflexiones de la instancia narradora se tornaba comprensible para el lector la relación entre los acontecimientos y la interioridad del héroe, de cuya transparente representación -no otra cosa sería la meta fundamental de todo poeta que se precie de tal- el lector podía extraer valiosas enseñanzas a ser aplicadas en su vida cotidiana.

Esto cambia, evidentemente, cuando el literato frustrado lee el Werther (HUBER 2003: 96). Ahora, la novela epistolar le parece "muy conveniente", ya que sirve mejor que ninguna otra forma para mostrar "la historia interior de un hombre y el modo en que su destino se desarrolla y se configura gradualmente a partir del fundamento de su carácter" (BLANCKENBURG 1981: 396). Es una afirmación casi contraria a lo que proponía en el Versuch, en lo que atañe a la forma epistolar.

En varios momentos de la reseña, el autor enfatiza lo que considera uno de los logros más destacables del creador del Werther: el haber creado un mundo verosímil en un sentido causal-psicológico. Dice Blanckenburg, en una suerte de "consejo" a los jóvenes poetas:

[E]s una necedad que, en un principio, para interesarnos, [los novelistas] pongan en su pequeño mundo cosas que no hay en la realidad, acontecimientos más grandes, fuera de lo ordinario, maravillosos, es decir, como si aquel solo pudiera estar hecho de engendros y monstruosidades. Esto último es innecesario, pues el fin último de interesarnos puede ser alcanzado mediante cosas sumamente sencillas y ordinarias, siempre y cuando se sepa hacer un uso poético de ellas. (BLANCKENBURG 1981: 420)

En función de esto, el reseñista destaca en la novela de Goethe el modo en que se reproducen verosímilmente "las peculiaridades de [las] costumbres" alemanas que ocasionan el disgusto de Werther en el episodio de la señorita de B... a la que Werther le ha abierto el corazón (carta del 15 de marzo de 1772). Lo que valora el crítico, que pone de nuevo el énfasis en la recepción, es que "acerca de ellas [i.e. las costumbres] no se nos dice más que lo que vemos diariamente" (BLANCKEnBurg 1981: 418). Más adelante, afirma:

Puede que, en una primera mirada, los presupuestos del poeta y el carácter atribuido a Werther parezcan demasiado definidos, demasiado singulares, como si no reflejaran la 
KOVAL, M. I. - La recepción de Las penas del joven Werther

probabilidad general de las cosas de este mundo, cosa que con razón exigimos aún de los caracteres poéticos. Sin embargo, cuando lo investigamos más a fondo, advertimos que los fundamentos del carácter de Werther se hallan a menudo en la naturaleza humana, y que las circunstancias propuestas no son para nada extraordinarias en su tipo, por más que muy raramente se encuentran ambas cosas juntas en la realidad. [...] la configuración y el ordenamiento apropiados de la situación, cuando no presentan rasgos improbables o aventurados, cuando no contienen imposibilidades u osadías, no solo le están muy permitidos al poeta, sino que son incluso aquello que lo distingue del mero narrador de historias. (BLANCKENBURG 1981: 428)

El reseñista distingue, así pues, entre el poeta (Dichter) y el "mero narrador" (“kahler Erzähler") según como sean el tipo de sucesos representados y sus relaciones con la realidad. El primero, el Dichter, está “obligado" a la verosimilitud; el segundo, el Erzähler, al parecer, no. El adjetivo "kahl” también puede traducirse como "estéril”; con ello, a lo anterior se agrega una evidente valoración negativa del "narrador", que inventa historias sin prestar atención a la relación con la naturaleza de la realidad y que, por eso, según parece estar pensando Blanckenburg, no es de utilidad pedagógica o vital para los lectores.

De cualquier modo, el punto en que más insiste (incluso de modo redundante) Blanckenburg es en la necesidad de una lectura empática de una novela como el Werther y de las obras del arte poética en general. La teoría de la novela que se halla in nuce en la reseña tiene premisas indudablemente sensibilistas (SAUDER 1978: 164s.). El reseñista afirma, en efecto:

Agradecemos al poeta, que le devuelve a la naturaleza todos sus derechos, que le arranca al desdén los múltiples lazos con los cuales la providencia une a los hombres entre sí, para hacerlos tanto más felices, y que busca atizar en la familia común de la humanidad el calor y la simpatía que tendría que animar mutuamente a los hijos de una misma casa. ¡Y el encanto de este sentimiento recompensa de la mejor manera a aquellos que son capaces de experimentarlo! Por cierto, no podemos demostrarles esto a los troncos insensibles; para esa gente este sentimiento resulta doloroso, insoportable. ¡ Pobre de estos debiluchos! ¿Es esta expresión demasiado dura para aquellos en quienes la naturaleza y la verdad están muertas o artificiosamente desplazadas? No queremos formar entusiastas [Schwärmer], pero lo sentimos vivamente en nosotros: que la sensibilidad es el regalo más noble de la Providencia, y que, adecuadamente cuidada y educada, genera las virtudes más humanas y la verdadera felicidad; y que el hecho de burlarse de ella se debe a una secreta envidia, pues la posesión de aquella nos hace felices e independientes de ciertos errores, necedades e ilusiones (BLANCKENBURG 1981: 434s.).

Para Blanckenburg, una novela como el Werther puede ayudar a desarrollar la capacidad de "participación afectiva" o "empatía" ("Teilnehmung”) del lector, que considera una herramienta clave para el bien común, ya que es ella la que, en todo caso, puede quitar la idea del suicidio de la mente de alguien que (como Werther) cree que lo ha perdido todo. La "buena” lectura, empático-racional, de la evolución del joven Werther 
KOVAL, M. I. - La recepción de Las penas del joven Werther

debe ser útil para detectar, en la vida, los caracteres con "propensión” al suicidio, para, así, poder ayudarlos a tiempo a comprender que la acción de quitarse la vida nunca puede ser el producto de una decisión fundada en la razón.

De ahí que el reseñista, a la manera de la "corrección" que hace Nicolai del personaje de Albert, critica la "postura" de Wilhelm, el destinatario de las cartas de Werther, a quien le reprocha su falta de empatía: "Si pudiéramos estar enojados con alguien, sería con este Wilhelm, que no fuera volando a salvar a Werther, dado que tanto lo apreciaba y lo quería; ¡debió poder hacerlo! Y si quisiéramos buscar algo inverosímil nos atreveríamos a encontrarlo en esto" (BLANCKENBURG 1981: 439), afirma en términos que hoy consideraríamos poco "apropiados" para un abordaje académico de la novela, si bien tal "enojo" con un personaje parece legitimarlo Blanckenburg en el propio epígrafe de Goethe al comienzo del Werther ${ }^{10}$.

Por lo demás, se reconoce en toda esta argumentación cierta influencia de un autor como Johann Elias Schlegel, una figura central de la Segunda Ilustración alemana y discípulo díscolo de Johann Christoph Gottsched. En efecto, en su Von der Unähnlichkeit in der Nachahmung (De la no-semejanza en la imitación) (1741), Schlegel rechazaba al crítico erudito como lector o espectador ideal y prefería a la persona libre de prejuicios que tiene suficiente "ternura del sentimiento" ("Zärtlichkeit des Gefühls") como para que las obras de arte lo "impresionen” (SCHLEGEL 1963: 513).

Lo dicho hasta aquí permite pensar a Blanckenburg como un representante típico de la Empfindsamkeit, que podríamos periodizar entre la década de 1740 y la época de publicación de las críticas de Kant, a partir de 1781. En un tono muy influenciado por el moral sense del conde de Shaftesbury ${ }^{11}$, el adversario principal que construye el reseñista en su discurso está representado sin dudas por los moralistas racionalistas a los que llama, como vimos en la cita anterior, "troncos insensibles", ${ }^{12}$ pero también, por ejemplo, "señores de sangre fría" (BLANCKENBURG 1981: 409), que son quienes fundan su rechazo de caracteres como Werther en "una cierta filosofía que enfría el corazón y agota el

\footnotetext{
${ }^{10}$ Así reza el epígrafe: "Und du gute Seele, die du eben den Drang fühlst wie er, schöpfe Trost aus seinem Leiden, und laß das Büchlein deinen Freund sein, wenn du aus Geschick oder eigener Schuld keinen nähern finden kannst" (GOETHE 1973: 6s.).

${ }^{11}$ Kondylis afirma que Blanckenburg debe ser ubicado en el contexto tardoilustrado del "redescubrimiento de Leibniz, limitado por la influencia de Shaftesbury" (1986: 576).

${ }^{12}$ Literalmente, en realidad, "bolas insensibles" ("fühllose Kloße”). El "Kloß” puede ser una bola de tierra o una albóndiga.
}

Pandaemonium, São Paulo, v. 24, n. 43, mai.-ago. 2021, p. 96-110 
KOVAL, M. I. - La recepción de Las penas del joven Werther

espíritu" (1981: 434), es decir, en el racionalismo que en Alemania seguía siendo preponderante.

Más arriba nos hemos referido al ideal de una lectura empático-racional porque para Blanckenburg no se trata nunca de rechazar la idea de racionalidad; hay a este respecto una nota al pie bastante llamativa en la que el reseñista reivindica la "investigación imparcial [que se lleva a cabo] a sangre fría” y critica a los "irracionalistas" que se oponen a toda regla y van aún más lejos "que la escuela de Rousseau":

Es sabido que en la actualidad algunas personas hablan y escriben mucho contra todas las reglas, o lo que llaman crítica; y estas personas que tienen el prestigio de hablar en contra de toda regla, porque en verdad ni siquiera saben bien qué son las reglas, podrían querer hacer suyo a un Werther como portavoz, valiéndose del pasaje recién mencionado. Es por esto que consideramos necesario recordarles a estos señores el hecho de que Werther, incluso en la ebullición de su corazón, puede despreciar las reglas sin perjudicarlas ni perjudicarse a sí mismo. Su situación y su modo de pensar lo disculpan enteramente; pero, al mismo tiempo, le impiden contrastar el mérito o desmérito de las reglas, así como apreciarlas convenientemente. Tan solo una investigación imparcial y llevada a cabo a sangre fría puede ser definitoria en lo que respecta a obras reflexivas y meditativas; ¿y no van a querer los buenos señores espantar y echar acaso totalmente del género humano a la pobre razón? Si lo desean, entonces es que no deben conocerla demasiado, o que no reflexionaron correctamente sobre las consecuencias, o que provienen de aún más lejos que la escuela de Rousseau, o incluso que ya no se acuerdan, aunque también ellos hayan recibido la capacidad de hablar de la naturaleza, de que, a pesar de todo, tuvieron que aprender incluso el ABC -y todo lo que saben- siguiendo reglas. (BLANCKENBURG 1981: 387s.)

Más allá de que Blanckenburg parece querer olvidarse de que el propio joven Goethe del Sturm und Drang es uno de los que van "más lejos" que Rousseau, y si obviamos también que no queda del todo claro a qué se refiere el autor de la reseña con lo de que Werther "puede despreciar las reglas sin perjudicarlas o perjudicarse a sí mismo", lo que sí podemos concluir es que el autor construye un lugar de enunciación desde el que parece sugerir que a los racionalistas lo que les falta es sentimiento y capacidad de empatía, sin querer por ello echar por la borda la idea de razón.

La lectura empfindsam no rechaza la racionalidad: no es Schwärmerei ni Empfindelei. El sensibilismo al que se adhiere en la reseña propone, justamente, un equilibrio entre "Kopf” y "Herz", la razón y el sentimiento, el análisis “frío” y, a la vez, "participativo".

En el pasaje que sigue (como en muchos otros), Blanckenburg se hace eco de ideas pedagógicas típicas del pensamiento de la Ilustración sensibilista, lo que, como veremos en seguida, contrasta con otros sectores de la reseña que sugieren ciertas nociones más novedosas para la época respecto de la recepción de las obras literarias:

Pandaemonium, São Paulo, v. 24, n. 43, mai.-ago. 2021, p. 96-110 
KOVAL, M. I. - La recepción de Las penas del joven Werther

Hemos conocido, del modo más palmario, el corazón humano en general y en especial todas las particularidades de un corazón sensible, pues hemos visto formarse y, por así decirlo, crecer ante nuestros ojos el entero modo de pensar y de sentir de Werther. Así que padres y maestros que tenéis hijos y pupilos en los cuales veis aparecer esta más elevada sensibilidad: ¡No le quitéis a su maleable alma, por medio de ejercicios destinados a hacerlos más fuertes, la fuerza para continuar! ¡No los encadenéis! ¡No los matéis! Pero ved en el infeliz Werther el camino que puede llegar a tomar, y aprended en su ejemplo, mediante el conocimiento exacto de sus procesos, a guiarlo mejor y en forma más segura. (BLANCKENBURG 1981: 437s.)

De acuerdo con la concepción del arte de Sulzer, Lessing y Mendelssohn, lo moral y lo poético debían ser entendidos como ámbitos diversos, sin llegar a desconocer nunca, con todo, la importancia de que la obra contribuya en último término al mejoramiento moral. Es ilustrativa en este sentido la reseña que en 1761 hace Mendelssohn de La nиеva Heloísa de Rousseau -recién publicada-, fundada en la idea de que las verdades morales no son, de por sí, convincentes, sino que es la fuerza emotiva que emana de una configuración poética completa y armónica la que, en todo caso, puede llegar a generar un cambio moral y un mejoramiento de las costumbres (MENDELSSOHN 1981). En este punto, la reseña de Blanckenburg es bastante coincidente con la propuesta de los amigos agrupados en torno a las Briefe, die neueste Literatur betreffend.

Lo cierto es que la idea de una función pedagógica de las novelas y el llamado a la recepción sensibilista, que Blanckenburg explicita hacia el final de su reseña-como lo delata la cita anterior, en la que se dirige sin más a los "padres y maestros" - no se dejan conciliar con facilidad con una segunda tesis sugerida en el texto y que se vincula a la en cierto modo novedosa postulación de la autonomía de la esfera artística. Esta noción aparece sobre todo en los pasajes en que se reflexiona acerca del suicidio de Werther. El reseñista combate una y otra vez la idea de que una novela pueda perjudicar la vida de una persona, llevándola en casos extremos a autoinfligirse la muerte. En esta línea, la intención que persigue es fundamentar la acción de Werther en términos de lo que él mismo llama, aristotélicamente, la "verdad poética".

En sus propias palabras: “[n]o queremos justificar a Werther; tan solo hablamos de la verdad poética" (BLANCKENBURG 1981: 403). La obra poética es "un todo fundamentado en sus partes" (BLANCKENBURG 1981: 428). En este sentido, entiende la acción trágica del joven enamorado (su suicidio) como una necesidad que se desprende, por un lado, de su carácter, y, por otro lado, de los distintos acontecimientos en los que se ve envuelto. Es decir, no se trata de pensar las obras de arte desde la perspectiva de su falta o no de moralidad, sino de su necesidad estética:

Pandaemonium, São Paulo, v. 24, n. 43, mai.-ago. 2021, p. 96-110 
KOVAL, M. I. - La recepción de Las penas del joven Werther

Sin dudas, el poeta podría haberle hecho tomar a Werther otro camino, y aun así haber producido un libro atractivo y útil, de haberlo querido así desde el comienzo. Pero, para decir que habría sido razonable que hiciera esto, hay que comprobar antes que las desventuras de Werther son o bien peligrosas o bien no lo suficientemente atractivas. El poeta no está obligado a ofrecernos siempre un ideal moral. No podemos enumerar aquí todos los motivos que nos llevan a sostener esta opinión. Pero si a los lectores únicamente se los puede interesar, en primer lugar, con el juego de las pasiones, la cuestión ya está comprobada (BLANCKENBURG 1981: 430) ${ }^{13}$.

En vista de esta fundamentación de la verdad poética en términos principalmente narrativos (dado tal carácter y dadas tales y tales circunstancias, el suicidio es una necesidad en el mundo narrado), que implica una distinción clara entre las esferas artística y moral, la reseña puede ser entendida como una polémica contra los moralistas (a quienes ya nos referimos). Pero también, a la vez, como un documento de transición hacia la autonomía absoluta de la esfera estética, y, en ese sentido, como una toma de distancia respecto de la posición asumida por los editores de las Briefe, es decir, Mendelssohn y sus dos amigos ${ }^{14}$.

El momento en que la ambigüedad o, si se quiere, contradicción a nuestro juicio irresuelta entre las dos tesis centrales de la reseña (recepción sensibilista y utilidad social versus autonomía de la esfera artística) queda más de manifiesto es cuando Blanckenburg asume una postura en la discusión acerca de si la publicación de la novela de Goethe ha hecho más infelices a las personas, llevándolas en algunos casos al suicidio. Así, dice:

No podemos investigar aquí si el conjunto de los infelices es ahora más grande que antes; pero lo que sí sabemos con certeza es que solo quien es totalmente infeliz se convierte en suicida, y que probablemente jamás ha ocurrido que la lectura de algún poeta haya hecho directamente infeliz a un hombre en el mundo real. Los motivos del crecimiento de este mal hay que buscarlos en cosas muy distintas, más poderosas y generales, que actúan sobre nuestras costumbres; y si se quisiera exigir del poeta que este debería tratar de contrarrestar la impresión que causan estas cosas, este podría argüir: Eso lo logra de la manera más efectiva la participación afectiva en las penas de los otros. Lo cierto es que incluso esta no puede hacer más que disipar los males, no curarlos (BLANCKENBURG 1981: 236).

Aquí, de nuevo, la novela tiene una finalidad extra-estética: ayuda al lector a, al menos, "disipar los males"; pero, al mismo tiempo, el reseñista afirma que es absurdo acusar a una novela de incrementar el número de suicidios: endilgarle esto al Werther es atribuirle un poder que no tiene (las causas de ese mal son "más poderosas y generales"),

\footnotetext{
${ }^{13}$ El subrayado es nuestro.

${ }^{14}$ Solo de transición, pues Blanckenburg está, por supuesto, muy lejos de, digamos, la concepción artística del Goethe de la década de 1790 o de los románticos. La autonomía de la esfera estética se reivindicará recién en el "periodo artístico" postkantiano (WEBER 1992: 11).
}

Pandaemonium, São Paulo, v. 24, n. 43, mai.-ago. 2021, p. 96-110 
KOVAL, M. I. - La recepción de Las penas del joven Werther

precisamente porque (parece sugerirse de un modo velado) es un objeto estético que, en tanto que tal, posee una lógica de funcionamiento propia. Como se ve, Blanckenburg parece no poder ponerse de acuerdo respecto de si la obra de arte (en este caso, el Werther) ha de ser leída con empatía o como una totalidad poética. En cualquier caso, afirma ambas cosas sin explicar cómo es posible conciliar los dos tipos de lectura, es decir, respectivamente, "sin" y "con" mediaciones.

\section{III}

La reseña de Blanckenburg es una reflexión acerca de la recepción de productos estéticos en la que se defiende la necesidad de un receptor empático que, a diferencia del "estricto juez moral", sea capaz de participar afectivamente en el destino del personaje (de Werther): esta "participación" no puede sino mejorar la sociabilidad, por lo que el arte tiene un efecto positivo en términos sociales. A su vez, con todo, en clara tensión con esto último, se sostiene que el lector debe acercarse a la novela entendiéndola como una totalidad que tiene una lógica de funcionamiento propia, es decir, que es autónoma y, por ende, no posee ningún tipo de responsabilidad ético-moral con respecto a los efectos que pueda llegar a causar en el receptor, que ha de acercarse a ella, entonces, como a un objeto al que el genio creador ha dotado de una existencia independiente.

En pocas palabras: hemos tratado de mostrar que Blanckenburg busca responder a la pregunta de cómo hay que leer una obra artística de dos modos que parecen a priori excluyentes: con empatía sensibilista (= la obra de arte tiene una función social) o con la mirada de quien entiende que es una totalidad cerrada (= la obra de arte agota su función en sí misma). Lo que quisimos mostrar es que, en la reseña en sí, en ningún momento queda claro si se trata de una contradicción (en caso de que lo sea) de la que el reseñista no es consciente o que deja inconscientemente sin resolver o que, sencillamente, no es capaz de subsanar con los medios teóricos de que dispone.

La otra posibilidad sería pensar que, muy lúcidamente, Blanckenburg se hace eco de la "voz doble" con la que el propio Goethe construye -él sí, sin dudas, muy consciente y revolucionariamente- su novela. ${ }^{15} \mathrm{Si}$ optamos por esto, toda la reseña se fundaría en la idea de que sentimos empatía en el nivel del discurso de Werther y, a la vez,

\footnotetext{
${ }^{15}$ Para la ambivalencia de Blanckenburg en el modo de leer las obras de arte, v. Heilmann 1992: 189-200.

Pandaemonium, São Paulo, v. 24, n. 43, mai.-ago. 2021, p. 96-110
} 
KOVAL, M. I. - La recepción de Las penas del joven Werther

consideraríamos la novela como un todo en el nivel del autor implícito con el que Goethe socava la legitimidad de lo enunciado por el personaje en el primer nivel. Acerca de la "voz doble" en la novela de Goethe, recuérdese que, en palabras de Vedda, el Werther "es a la vez una novela sentimental y una reflexión crítica acerca de dicho género" (VEDDA 2015: 62).

De cualquier modo, creemos que la duda respecto del grado de penetración del crítico ilustrado en su análisis de la compleja estructura del texto de Goethe queda sin resolverse (¿Es Werther una figura con la que uno se identifica o un elemento de un sistema estético? ¿O las dos cosas? ¿Y cómo?). Blanckenburg toma los dos niveles de análisis (lectura identificatoria con el personaje y conciencia de la autonomía estética en atención al poeta) como igualmente válidos y no parece ser consciente ni estar preocupado por la ambivalencia resultante; de igual modo, no afirma que los dos niveles sean una propiedad del objeto, es decir, de la novela de Goethe, que él simplemente reproduciría como operación crítica.

No resulta claro, tampoco, que esta "contradicción” sea salvada por las -sin dudas, muy evidentes- premisas leibnizianas del pensamiento de Blanckenburg, según las que el efecto positivo de la obra sobre el lector -que se logra, como vimos, en virtud de la "participación" emocional-afectiva en las penas de Werther- estaría asegurado a priori, por más que, en sí, la novela, en tanto artefacto estético, no esté obligada a "mejorarlo" como ser humano integrante de una comunidad (v. HeILMANN 1992: 196). En todo caso, entendemos que atribuirle al autor el sagaz reconocimiento de la novedosa técnica de la "voz doble" insertada por Goethe en la novela es llevar la simpatía por el literato frustrado y crítico literario demasiado lejos.

\section{Referencias bibliográficas}

BlancKenburg, F. Die Leiden des jungen Werthers. In: Weber, E. (ed.). Texte zur Romantheorie, v. 2. 1732-1780. München: Wilhelm Fink, 1981, 392-441.

BLANCKENBURG, F. Versuch über den Roman. Berlin: Zenodot, 2008.

De BoOR, H.; Newald, R. Kräfte des Beharrens und des Fortschritts. In: De BooR, H.; Newald, R. (eds.). Geschichte der deutschen Literatur. Múnich: Beck, 1967, 105-160.

GoETHE, J. W. Goethes Werke. Hamburger Ausgabe. Múnich: Beck, 1973.

HaSs, H.-E. Werther-Studie. In: Alewyn, R.; Hass, H.-E.; Heselhaus, C. (eds.). Gestaltprobleme der Dichtung. Bonn: Bouvier, 1957, 83-125.

Heilmann, M. Die Krise der Aufklärung als Krise des Erzählens. Tiecks «William Lovell» und

Pandaemonium, São Paulo, v. 24, n. 43, mai.-ago. 2021, p. 96-110 
KOVAL, M. I. - La recepción de Las penas del joven Werther

der europäische Briefroman. Stuttgart: Metzler, 1992.

Huber, M. Die Text als Bühne. Theatrales Erzählen um 1800. Göttingen: Vandenhoeck \& Ruprecht, 2003.

KimPel, D.; Wiedemann, C. (comps.). Theorie und Technik des Romans im 17. und 18. Jahrhundert. Tübingen: Niemeyer, 1970.

KONDYLIS, P. Die Aufklärung im Rahmen des neuzeitlichen Rationalismus, Múnich: Beck, 1986.

Koval, M. Vocación y renuncia. La novela de formación alemana entre la Ilustración y la Primera Guerra Mundial. Buenos Aires: Editorial de la Facultad de Filosofía y Letras de la UBA, 2018.

LEISTNER, B. Goethes ,Werther' und seine zeitgenössischen Kritiker. In: KELLER, W. (ed.). Goethe-Jahrbuch, v. 112. Weimar: Hermann Böhlaus, 1995, 71-82.

LuKÁCs, G. La novela. In: LuKÁcs, G. Escritos de Moscú. Trad. de M. Vedda y M. Koval. Buenos Aires: Gorla, 2011, 29-76.

Mendelssohn, M. Rousseaus Julie. In: WeBER, E. (ed.). Texte zur Romantheorie, v. 2.: 17321780. München: Wilhelm Fink, 1981, 216-227.

SAUDER, G. Subjektivität und Empfindsamkeit im Roman. In: HINCK, W. (ed.). Sturm und Drang. Ein literaturwissenschaftliches Studienbuch. Kronberg: Athenäum, 1978, 163-174.

SCHLEGEL, J. E. Ausgewählte Werke. Weimar: Arion, 1963.

SElbmann, R. Der deutsche Bildungsroman. Stuttgart: Metzler, 1994.

SUlzER, J. G. Imaginação (Belas-artes). Trad. y notas de U. Razzante Vaccari. Rapsódia, n. 4, 123-140, 2008.

VEDDA, M. Leer a Goethe. Buenos Aires: Quadratta, 2015.

WEBER, E. Blanckenburg. In: KILLY, W. (ed.). Literatur Lexikon. Autoren und Werke deutscher Sprache. München: Bertelsmann, 1992, 10-11.

WEBER, E. Nachwort. In: WeBER, E. (ed.). Texte zur Romantheorie, v. 2.: 1732-1780. Múnich: Wilhelm Fink, 1981, 606-633. 